\title{
A TERRA COMO BEM-COMUM NA MEMÓRIA DO DIREITO BRASILEIRO
}

\section{THE LAND AS WELL COMMON IN THE MEMORY OF BRAZILIAN LAW}

\author{
Sandra Regina Martini* \\ Vanessa Chiari Gonçalves** \\ Bárbara Bruna de Oliveira Simões***
}

\begin{abstract}
Resumo: O artigo trata da terra, memória e direito com o objetivo de reconsiderar a terra como bem comum da humanidade, as referências jurídico políticas e sociais utilizadas são as brasileiras até a década de 80, pois entendemos que a nova Constituição embora apresente avanços significativos, não é suficiente para enfrentar a complexidade do direito ao bem comum terra. $\mathrm{O}$ direito precisa retomar a memória para cumprir sua função de evitar e compor conflitos, ou seja, o direito tem uma função preventiva, deve operar prevenindo e compondo conflitos advindos das mais diversas instâncias, em especial, neste artigo, dos Movimentos Sociais, sem os quais não é possível pensar na terra como bem da comunidade, pois são os movimentos sociais que trazem para o cenário jurídico-político a conflitualidade da sociedade, por isso são sistemas autoreferenciais de comunicação, que se inserem nos sistemas jurídico e político como reação da própria sociedade diferenciada funcionalmente. Assim, constrói-se a ideia de terra como um bem comum da humanidade, passando pela cooperação entre o local e o global.
\end{abstract}

Palavras-chave: Bem comum; Brasil; direito; memória; terra.

\begin{abstract}
The article deals with land, memory and law with the objective of reconsidering land as a common good of humanity, the legal and political references used are Brazilian until the 1980s, since we understand that the new Constitution does is sufficient to face the complexity of the right to the common good land. The law needs to retake the memory to fulfill its function of avoiding and composing conflicts, that is, the right has a preventive function, it must operate preventing and composing conflicts arising from the most diverse instances, especially in this article of the Social Movements, without which it is not possible to think of the land as a community good, because it is the social movements that bring to the juridical-political scenario the conflict of the society, for that reason they are self-referential systems of
\end{abstract}

\footnotetext{
* Doutora em Evoluzione dei Sistemi Giuridici e Nuovi Diritti pela Università Degli Studi di Lecce. Pósdoutorado em Direito (Roma Tre, 2006) e em Políticas Públicas (Universidade de Salerno, 2010). Pesquisadora Produtividade $2 \mathrm{CNPq}$, professora do Centro Universitário Ritter dos Reis Laureate International Universities (UniRitter), professora-visitante no programa de pós-graduação em Direito da UFRGS (PPGD). Coordenadora do Mestrado em Direitos Humanos do Centro Universitário Ritter dos Reis Laureate International Universities. E-mail: srmartini@terra.com.br.

** Doutora em Direito pela UFPR, Mestre em Ciências Criminais pela PUCRS, Professora do Departamento de Ciências Penais e do Programa de Pós-Graduação em Direito da UFRGS, pesquisadora e advogada em Porto Alegre. E-mail: vanessachiarigoncalves@gmail.com.

*** Advogada. Mestranda em Direitos Humanos pelo Centro Universitário Ritter dos Reis Laureate International Universities/RS. Bolsista Capes. E-mail: barbarabsimoes@gmail.com.
} 
communication, that are inserted in the legal and political systems as a reaction of the own society functionally differentiated. Thus, the idea of land is constructed as a common good of humanity, through the cooperation between local and global.

Keywords: Common good; Brazil; memory; right; land.

\section{INTRODUÇÃO}

Eu sou a terra, eu sou a vida. Do meu barro primeiro veio o homem. De mim veio a mulher e veio o amor. Veio a árvore, veio a fonte. Vem o fruto e vem a flor. Eu sou a fonte original de toda vida. Sou o chão que se prende à tua casa. Sou a telha da coberta de teu lar.

A mina constante de teu poço. Sou a espiga generosa de teu gado e certeza tranqüila ao teu esforço.

Sou a razão de tua vida.

A terra é a vida e a vida só é possível através da terra, como demonstra Cora Coralina em "O Cântico da Terra". Se terra e vida estão interligadas, então o direito à terra também está vinculado à possibilidade de vida, de sobrevivência, onde fruta e flor podem ser compartilhadas, ainda que a história nos mostre o contrário. O desafio atual é entender a terra como bem comum da humanidade, como direito humano necessário à vida, por isso, essa reflexão inicia-se com a proclamação da fonte original de toda a vida, do chão onde vivemos e crescemos. A mãe-terra não é apenas uma simbologia de algumas populações, mas é uma "Mãe universal", a impossibilidade de acesso a esta "mãe" é também a impossibilidade de acesso aos direitos humanos.

$\mathrm{O}$ acesso à propriedade da terra no Brasil se constitui como um processo histórico ${ }^{1}$, longo e permeado por uma perspectiva patrimonialista, por uma indistinção entre o público e o privado $^{2}$ desde a colonização por Portugal. Ainda que muitos avanços normativos tenham sido conquistados no tocante à regularização fundiária e ao acesso à terra, ainda existe uma distância abissal entre o projeto constitucional e a distribuição da terra no Brasil, de forma a cumprir com a ideia de bem comum dentro da R. Fac. Dir. UFG, v. 42, n. 1, p.11-31, jan/abr. 2018 
A terra como bem-comum na memória do direito brasileiro

sociedade. Movimentos sociais de campesinos sofrem com a estigmatização de suas lutas, amparada por um simbolismo construído com base em preconceitos arraigados, repressão estatal e midiática e um profundo desconhecimento de nossa história. Junto com esta carga de preconceitos, encontra-se a violação dos direitos humanos destas populações, que buscam o ideal da terra como um bem comum.

Desse modo, esse artigo busca responder ao seguinte problema de pesquisa: Atualmente, podemos falar na terra como um bem comum da humanidade? Objetiva-se estudar quais são os aspectos históricos relacionados ao acesso à terra no Brasil que contribuem para a dificuldade de se concretizar o objetivo programático de melhorar a distribuição da terra no país até o período pré-Constituição de 1988.

Com frequência esquecemos fatos relevantes da nossa construção enquanto sociedade, por isso há a necessidade do resgate da memória. Assim, a pesquisa propõe um resgate histórico, para que seja preservada a memória das lutas pela terra em nosso país, envolvendo os acontecimentos mais marcantes do período imperial e do período republicano anteriores à Constituição da República, de 1988. Esclarece-se que não se optou por delimitar um período histórico mais reduzido porque existem aspectos relevantes para a compreensão do problema, que merecem destaque, tanto no período imperial quanto no período republicano da história do Brasil.

Embora tenham ocorrido alterações legislativas importantes, entende-se que não houve uma ruptura ou uma descontinuidade significativa entre ambos os períodos no que diz respeito ao acesso à terra. Assim, pretendemos apenas construir a memória necessária do direito à terra, com o objetivo de relembrar e, ao mesmo tempo, de prospectar futuros, por meio da técnica da revisão bibliográfica e do método dialógico de abordagem.

\section{MOVIMENTOS SOCIAIS DA TERRA E MEMÓRIA}

De mim vieste pela mão do Criador e a mim tu voltarás no fim da lida. Só em mim acharás descanso e Paz. Eu sou a grande Mãe Universal. Tua filha, tua noiva e desposada. A mulher e o ventre que fecundas. 
As memórias coletivas se constituem a partir de relatos históricos. Esses relatos são versões sobre acontecimentos que se constroem por entre as lentes do observador ou intérprete e que, por isso, não estão imunes às críticas e às divergências. Por isso a importância de se consultar os documentos históricos para que eles auxiliem na compreensão da realidade da distribuição de terras no Brasil, buscando desvelar o sentido da terra como bem comum.

$\mathrm{Na}$ perspectiva da memória é importante destacar que os movimentos sociais sempre marcaram o processo evolutivo da humanidade $^{3}$. Inicialmente, os indivíduos se "movimentavam" em busca de novas terras, já que aquelas nas quais viviam estavam com suas possibilidades esgotadas. Os primeiros movimentos da sociedade são caracterizados pelo "ato ou processo de mover-se"4, estando já implícita a necessidade de alguma forma organizativa que os impulsionasse. Ainda que a organização inicial fosse muito rudimentar, era ela que fazia com que novos locais para a ocupação fossem definidos.

Vale ressaltar que as pesquisas sobre estas "mudanças" de território têm sido objeto de estudo da História, da Arqueologia, da Geografia e de outras disciplinas afins. A Sociologia, por sua vez, passa a se ocupar deste tema somente em anos recentes. Assim, Giddens traduz, de forma genérica, o approccio sociológico de movimento social, caracterizando-o como marca do mundo contemporâneo, tendo em vista que estes movimentos ultrapassaram a ocupação de terras, embora o problema da distribuição de terras ainda persista.

Pretendemos demonstrar que, no caso específico da "luta pela terra", o movimento é muito mais antigo. Ele adquire na modernidade um "novo" significado e uma nova organização. Portanto, estudar a terra significa entender os movimentos - no sentido de ato ou processo de mover-se - que os indivíduos realizam para tentar desvelar as razões pelas quais vivemos nela e com ela. Este é o problema originário da existência humana, o qual, com o processo evolutivo da sociedade, foi se tornando cada vez mais complexo. Da mesma forma, os movimentos também aumentaram a sua complexidade.

Inicialmente, os seres humanos demarcavam o seu território e saíam em busca de novos espaços. Essa vontade incessante por e de terra fez com que ela começasse a ser demarcada, apropriada e explorada. Nesse processo, os seres humanos esqueceram de que sob e sobre esta terra existiam outros seres vivos, cuja soberania foi 
sendo "ignorada". O reflexo disso é sentido ainda na atualidade, quando há a necessidade de se resguardar o meio ambiente pela proteção internacional dos direitos humanos, em face do descaso e da sua exploração desenfreada e egoísta.

No processo de multiplicação, o ser humano foi tendo a ideia da apropriação da terra como sua. O seu sentido de propriedade inicial não era o da propriedade para conservar, mas para explorar. Então, uma vez mais, com o processo civilizacional da sociedade aparece a necessidade de uma demarcação jurídica dos territórios ${ }^{5}$ e das propriedades privadas ${ }^{6}$.

As demarcações da terra e o nascimento do Direito estão ligados e relacionados. Carl Schmitt afirma que o Direito nasce da terra e, portanto, tem um tríplice significado relacionado com a terra. $\mathrm{O}$ mesmo autor refere que "a terra, na linguagem mítica, é a mãe do Direito". Ele alude a uma tríplice raiz do conceito de direito e de justiça. Assim, primeiro tem-se a justiça da terra, que é conhecida por cada agricultor (a fadiga e o trabalho, a seminação e a cultivação feitas pelo homem são recompensados com justiça pela terra por meio do crescimento e da colheita); após, tem-se que as delimitações do terreno cultivado pelo homem são naturalmente feitas pelos campos, prados e bosques, ou seja, são subdivisões evidentes; por último, Carl Schmitt afirma que a terra, no seu próprio solo, tem firmado o seu limite e estabelece a sua própria delimitação (pedras, muros, edifícios...) e é nisto que se evidenciam os ordenamentos e as localizações da convivência humana. Nessas delimitações, as famílias, as estirpes, os tipos de propriedade e, também, as formas de poder e de domínio se fazem publicamente visíveis.

No contexto da luta pela terra inserem-se os trabalhadores rurais sem-terra, que têm, muitas vezes desde que nasceram, estreita relação com a terra. Hoje, porém, não exercem o direito de estar e de trabalhar nela. Por isso, lutam para efetivar este direito. Lutam porque, analisando a história, perceberam que a "pressão popular" é o único meio de se conseguir algo. Por isso eles pressionam, fazem campanhas, marchas, ocupações, tudo mediante prévia organização.

Os trabalhadores rurais sem terra lutam com tanto empenho pela efetivação de direitos ${ }^{7}$, não apenas no tocante ao acesso à terra e pela reforma agrária mais ampla, mas também pelo direito à dignidade humana, que dificilmente abrirão mão deles ou não os preservarão depois de conquistados. 


\section{MEMÓRIA DO DIREITO E DA TERRA NA HISTÓRIA DO BRASIL}

Sou a gleba, a gestação, eu sou o amor. A ti, ó lavrador, tudo quanto é meu. Teu arado, tua foice, teu machado. $O$ berço pequenino de teu filho. $O$ algodão de tua veste e o pão de tua casa. E um dia bem distante a mim tu voltarás.

O acesso à terra, no Brasil, aconteceu por meio de decretos, alvarás e ordens régias. Este fato marca a necessidade que se impõe de termos sempre antes a lei e depois o direito a determinados bens para a sobrevivência. Observamos que todo o processo de evolução histórica da sociedade brasileira passou e passa pelas determinações “da lei”, a qual é sempre acatada "pelos homens do bem”, mas é pouco cumprida quando trata dos "homens da sociedade". Em outros termos, toda a legislação que deveria proporcionar o acesso à terra para quem não a tem, acaba produzindo um efeito contrário, qual seja, a manutenção dos latifúndios ${ }^{8}$.

O estudo sobre a legislação, de modo geral, revela-nos a estreita ligação entre a terra e o direito. Reportamo-nos a Carl Schmitt, o qual expõe de forma ilustre a relação entre terra e direito. Vejamos:

\footnotetext{
Cosi la terra risulta legata al diritto in un tríplice modo. Essa lo serba dentro di sé, come ricompensa Del lavoro; lo mostra in sé, come confine netto; infine lo reca su di sé, quale contrassegno pubblico dell'ordinamento. Il diritto è terraneo e riferito allá terra. Il diritto è terraneo e riferito alla terra. É quanto intende il poeta quando, parlando della terra universalmente giusta, la definisce justissima tellus. (SCHMITT, 1991, p.20)9.
}

As primeiras demarcações de terra definiam o que era direito de um e não do outro, bem como todas as punições caso a propriedade fosse maculada. É claro que somente mais tarde, a partir da existência de um Estado, esse direito vai se "oficializar". Conhecemos, porém, desde os povos primitivos, a importância "jurídica” destas demarcações. Os termos "oficializar" e "jurídica" estão destacados porque entendemos que, embora os povos primitivos não tivessem um código ou uma definição do que é legal e ilegal, ou seja, um aparato burocrático, conheciam formas jurídicas as quais hoje continuamos pesquisando ${ }^{10}$. 
O Tratado de Toledo, celebrado em 6 de março de 1480 entre Portugal e Espanha, determinava que Portugal detinha o poder sobre as águas e terras ao sul das Canárias. Sendo assim, Portugal já dominava, mesmo que formalmente, o território brasileiro, ainda antes da viagem de Cristóvão Colombo. Nesse momento, nota-se que o direito, além de ter uma forte ligação com a demarcação de terras, também apresentava um vínculo, talvez não com tanta intensidade, em relação ao mar. Pode-se dizer, então, que o Tratado de Toledo foi o primeiro marco divisório das terras brasileiras.

Em 07 de junho de 1494 foi assinado o Tratado de Tordesilhas, elaborado porque Portugal pretendia tomar posse das terras (conhecidas e/ou desconhecidas) de todo o Atlântico Sul. Nota-se que o Brasil "nasce" vinculado ao "poder divino" e ao "poder do Rei", como podemos observar pela introdução e pela conclusão do Tratado" ${ }^{11}$ Embora "Deus" esteja presente neste Tratado, não nos parece que esta presença tenha impedido todo o processo de exploração que houve em toda a América. Processo esse do qual "Deus", seguramente, seria contrário!

Alguma coisa de diferente das pretensões das leis divinas aconteceu nestes territórios, pois a terra não significou nem libertação, nem fonte de dignidade. O processo de formação da "nova" sociedade brasileira ocorreu de forma imparcial, ou seja, mesclaram-se as decisões e as influências daqueles que se diziam autorizados pelo sistema do Direito e da Religião ${ }^{12}$. "Aquilo" que mais tarde vai se efetivar como colônia de Portugal, foi "descoberto" em 22 de abril de 1500. Em termos jurídicos, este marco não foi tão importante quanto o Tratado de Tordesilhas, já que as terras brasileiras já eram conhecidas na Europa, embora a história oficial, ainda nos dias de hoje, apresente este fato como duvidoso. Sabe-se que somente por meio deste marco é que o que havia sido definido no Tratado passa a ser conquistado.

Para conservar essa propriedade, a Coroa Portuguesa estabeleceu as primeiras feitorias, as quais eram úteis para se fazer o comércio de pau-brasil, funcionando como organizações comerciais e militares. As feitorias (1511) formaram o processo inicial de ocupação do território nacional. As mais importantes instaladas no Brasil foram a de Cabo Frio, em 1511, e a de Pernambuco, em 1516. As feitorias foram imprescindíveis para o desenvolvimento da economia brasileira e para a definição do modelo de ocupação das nossas terras. Neste momento histórico, a sociedade ainda não conhecia a diferenciação funcional ${ }^{13}$, por isso, os poderes econômico, político, religioso e jurídico eram confundidos. 
A "doação" das terras brasileiras ocorreu após as feitorias e destinava-se aos portugueses que almejavam fortuna no Brasil. O Rei, em 1534, destinou porções de terra a nobres portugueses, as quais foram denominadas "Capitanias Hereditárias", que constituíam uma espécie de "privatização da colonização" (CASTRO, 2003, p.303). Assim, no período ao qual se faz referência, o acesso à terra poderia ser alcançado por ocupação ou por doação real. A ocupação significava uma lesão ao "meu jurídico", como afirmava Kant. Ou seja, a ocupação era uma forma ilegal de acesso à terra, enquanto que a doação era a forma legal. O que ocorreu no Brasil foi que os fazendeiros obtinham acesso à terra por meio de doações e as demais "raças e povos" por meio da ocupação $^{14}$.

Durante o Governo-Geral (até 1808) se implementaram as sesmarias e a política de colonização. As sesmarias no Brasil, entretanto, não eram doações a quem quisesse cultivar a terra, mas sim a quem tivesse capital para explorá-las. Dois séculos mais tarde, pouco mudou. Embora não conheçamos mais como sesmarias, a forma parece não ter se alterado tanto. Talvez se tenham aprimorado as formas de apropriação legal, mas não justa, da terra. Na sociedade brasileira atual, explora a terra quem possui recursos. Quem não é tão "afortunado", trabalha na terra do outro, como meeiro ou arrendatário, pagando ao proprietário por isso.

Depois da segunda metade do século XVII começaram a ser identificados os grandes latifúndios no Brasil. Ingressou-se, então, em um novo período da história brasileira, marcado pela Colônia do Açúcar e pelo Ciclo do Ouro, em que foi encontrada grande quantidade de jazidas no território brasileiro. Tal fato exigiu e despertou uma atenção estatal mais acentuada, ensejando a criação de legislação específica para administrar e controlar essa atividade.

Assim, temos uma evolução evidente para a diferenciação e a estruturação do sistema do Direito, o que constituirá futuramente o Brasil independente. Notem-se, porém, duas questões: a primeira, como já referimos no início, é a ideia de que o direito está vinculado à terra, ou à sua demarcação, ou à sua exploração; a segunda, é a relação estreita entre sistema da economia e sistema da política.

A outorga da primeira Constituição brasileira, por D. Pedro I, ocorreu em 1824. Essa Constituição foi elaborada por um Conselho de Estado composto de seis ministros e quatro membros selecionados pelo Imperador, que tinham um prazo de quarenta dias para elaborá-la. Foi uma Constituição imposta que recebeu fortes 
influências da Revolução Francesa. Celebrava o caráter do liberalismo individualista, mas não contemplava os princípios da igualdade e da liberdade, distanciando-se de qualquer defesa dos interesses coletivos.

A Constituição do Império, em seu artigo 179, garantia aos cidadãos que não gozavam de direito de voto ou de concorrer às eleições os direitos civis de liberdade, propriedade e segurança da vida e dos bens: "A inviolabilidade dos direitos civis e políticos dos cidadãos brasileiros, que tem por base a liberdade, a segurança individual e a propriedade, é garantida pela Constituição do Império [...]” (LOPES, 2002, p. 313). É claro que esta "garantia" jurídica, neste caso específico, é a propriedade da terra. Hoje, temos cidadãos e cidadãos não-cidadãos. Ou seja: se no Império a condição sine qua non para ser cidadão de fato era ser proprietário, hodiernamente para ser cidadão pleno é preciso ou ter propriedade ou ter propriedade. Em outros termos, na atualidade a propriedade pode ser entendida em uma dimensão mais ampla que aquela concernente à terra. Porém, somente têm a cidadania assegurada aqueles que podem “pagar” por ela. É claro que no plano jurídico-político esta nossa afirmação pode ser derrubada ou enfrentada. Entretanto, no plano fático e real, temos aqueles direitos que podemos "adquirir".

Pode-se afirmar, ainda, que a formação de um Estado nacional independente, no Brasil, ocorreu sem que houvesse alterações na organização da economia e da sociedade. Essa transição se deu "[...] sem que o regime de castas e estamentos sofresse qualquer crise, pois ele constituiu a base econômica e social da transformação dos 'senhores rurais' numa aristocracia agrária". (FERNANDES apud CERQUEIRA, 2004, p. 62)

No entanto, em 1850, foi aprovada no Brasil a Lei $\mathrm{n}^{\circ} 581$, chamada Lei Eusébio de Queiroz, que tratava da repressão do tráfico de africanos, considerados propriedade no território brasileiro. Com a proibição do tráfico de escravos, como bem ressalta Flávia Lages de Castro (CASTRO, 2003, p.398.), o Brasil vivenciou consequências econômicas e ideológicas. O movimento abolicionista crescia e ganhava força. Contra este movimento se manifestavam os fazendeiros, que perderiam a mão-deobra barata e eficaz que sustentava os seus latifúndios.

A primeira Constituição da República, de 1891, foi marcada pela influência do Liberalismo. Essa Constituição alterou a sua redação no concernente à propriedade, mas conservou a mesma essência da Carta Magna anterior. Criou a transferência das terras de uso público da União para os Estados. Durante a Primeira República, as 
classes proprietárias dominavam e controlavam o Estado, pois detinham o controle das dívidas dos estados, transformando essas dívidas em dívidas públicas. Assim, “[...] este crédito dos grandes proprietários é sempre garantido pelo Estado, corrigido astronômica e impiedosamente pelos tribunais e termina sendo pago pela classe trabalhadora ou pelos economicamente mais fracos.” (LOPES, 2003, p.381)

Em 1932 o Brasil viveu a Revolta Constitucionalista, uma guerra civil iniciada pelo estado de São Paulo contra o Governo Federal. O escopo utilizado para essa Revolta foi a necessidade de uma Constituição. Tem-se, então, que em 5 de abril de 1933 foi convocada a Assembleia Constituinte, a qual estava representada por oligarquias estaduais e, também, por representantes classistas eleitos nos sindicatos (CASTRO, 2003, p.445). Em 1934 foi publicada, então, uma nova Constituição, marcada por guerras entre países, que culminavam no reforço do nacionalismo. Essa Constituição limitou o direito de propriedade, subordinando-o ao interesse social ou coletivo e garantindo ao Estado a faculdade de poder usar a propriedade particular em casos especiais ${ }^{15}$.

Advindo o golpe do Estado Novo, em 10 de novembro de 1937 Getúlio Vargas fechou o Congresso e apresentou a nova Carta Constitucional. A Constituição de 1937 trazia a possibilidade de se ter a propriedade limitada pelo interesse social. Entretanto, essa possibilidade não estava assegurada ou garantida, sendo muito improvável que ocorresse. Em 1945, Getúlio Vargas foi deposto do poder pelos militares.

O Estatuto da Terra foi publicado em 30.11.1964. Tal Estatuto teve indiscutível importância, uma vez que legitimou a luta pela terra no Brasil. Entretanto, ele foi realizado nos anos da ditadura militar, em que, conforme Flávia Lages de Castro, “[...] o Estado de Direito era, neste momento da história do país, o Estado dos Militares" (CASTRO, 2003, p. 688). Por isso, os resultados que produziu serviram mais para a consolidação e solidificação dos latifúndios que para o acesso de todos à terra. Foram anos em que houve um grande deslocamento do eixo econômico, que migrou do rural para o urbano-industrial. A repressão política da época dificultou a criação de uma política agrária eficaz.

Em 1967, com o Ato Institucional $n^{\circ} 4$, o Congresso Nacional foi convocado para votar uma nova Constituição, cujo texto, bem como o da Emenda Constitucional $\mathrm{n}^{\circ}$ 1 de 1969, consagraram a função social da propriedade como princípio constitucional. 
Entretanto, nada expressou sobre o uso da propriedade vinculado ao bem-estar social, tampouco sobre a justa distribuição da propriedade. Em 1983 o Brasil viveu a campanha “Diretas Já!”, pela qual se requisitava as eleições diretas para a presidência da República. Por meio de eleições indiretas, no dia 15 de janeiro de 1985, Tancredo Neves foi eleito presidente do Brasil, mas faleceu logo em seguida, de forma que o vicepresidente, José Sarney, se tornou o primeiro presidente civil após um longo regime de Ditadura Militar (1964 - 1985).

Com José Sarney no poder houve uma grande reforma política que permitiu

a convocação de uma Assembleia Nacional Constituinte para a elaboração da Constituição em vigor, foi elaborada entre 1987 e 1988 e promulgada no dia 5 de outubro de 1988. A Constituição Cidadã, em seu artigo 5º, incisos XXII e XXIII, garante o direito à propriedade, mas assegura que ela deverá cumprir a sua função social.

Ao longo desta análise histórica do direito brasileiro, bem como da terra no direito brasileiro, utiliza-se a memória como ferramenta de construção de críticas quanto ao valor que o nosso ordenamento jurídico atribui à terra. Podemos observar que, ao longo da história do Brasil, a terra sempre está presente como forma de diferenciar as pessoas, como forma de ostentação de riquezas. Contudo, paradoxalmente, os movimentos sociais sempre lutaram pela terra como bem comum da humanidade. A partir da Constituição Federal de 1988, podemos continuar a luta por este bem comum.

\title{
4. A TERRA COMO BEM COMUM DA HUMANIDADE
}

\author{
$[\ldots]$ \\ E no canteiro materno de meu seio \\ tranqüilo dormirás. \\ Plantemos a roça. \\ Lavremos a gleba.
}

Os bens comuns da humanidade passam por um forte processo de privatização, desse modo refletem claramente a paradoxalidade da sociedade atual, onde a inclusão universal gera ao mesmo tempo, e muitas vezes com maior intensidade, uma exclusão. Observamos que na relação da terra com o direito, há contradições fundamentais, merecendo destaque a existência de uma proteção jurídica e política que não protege e, de forma contraditória, em muitos casos, oferece mecanismos para a apropriação do bem comum terra ${ }^{16}$. 
O estudo da terra como bem comum da humanidade ${ }^{17}$ reaparece nos dias atuais ${ }^{18}$, pois nunca se teve tantas leis que protegem a terra, ao mesmo tempo em que ela é privatizada ${ }^{19}$. Para refletir a terra nessa perspectiva, é preciso entender o novo significado que a luta pela terra adquire: a terra como um direito. A partir daí surge, também, uma nova organização dos sistemas sociais.

$\mathrm{O}$ direito à terra, fruto de um processo de lutas sociais, passa a ser recentemente entendido como um bem da comunidade que, ao longo do processo evolutivo, percebeu que a cidadania só é possível aliada a direitos e deveres. Uma comunidade que reconhece esse processo de aquisição de direitos é aquela que proporciona uma vida saudável para os indivíduos. A crescente solicitação e, ao mesmo tempo, a negação/efetivação de direitos fundamentais tem no direito à terra um locus especial.

A noção de bem comum vem sendo estudada desde os tempos gregos, período desde o qual o conceito vem ampliando sua abrangência. $\mathrm{O}$ questionamento sobre esse conceito segue sendo objeto de estudos políticos, jurídicos e filosóficos. Além da necessidade de uma definição mais apurada de bem comum, também se questiona: quando o bem é comum? Quem cuida do bem comum? Estes questionamentos não podem mais ser respondidos fora do contexto de uma sociedade não ideal, mas de uma sociedade que é como é, ou seja, uma sociedade altamente complexa, contingente e paradoxal. Atualmente, não podemos mais pensar em sociedades perfeitas, mas nas sociedades que temos, onde os espaços públicos apresentam novas dimensões ${ }^{20}$.

Retomar as definições e dimensões dos bens comuns significa revisitar noções como amizade, pactos, acordos, inclusão, em uma palavra: retornar à fraternidade como um código capaz de desvelar paradoxos, inclusive o paradoxo do público. Além disso, refletir sobre o direito à terra como bem comum implica em retomar o conceito de comunidade. Ou ainda, a amizade aparece na sociedade diferenciada funcionalmente como diferença entre interação de identidade individual e as relações burocráticas dos mecanismos internos dos sistemas sociais. Como afirma Eligio Resta (2005, p. 12), exatamente porque introjeta a diferença entre interação e a sociedade, a amizade reproduz no interior toda a ambivalência da diferenciação.

É importante referir que essa proposta se torna ainda mais desafiadora no Brasil porque a racionalidade inerente à cidadania não chegou a ser construída aqui. R. Fac. Dir. UFG, v. 42, n. 1, p.11-31, jan/abr. 2018 
A terra como bem-comum na memória do direito brasileiro

Nossas elites urbanas e rurais abdicam dessa racionalidade para manter as coisas ordenadas como estão. A cidadania, que é indispensável para a construção de uma democracia concreta e fraterna, pressupõe uma relação entre a cidade e o indivíduo. $O$ problema é que essa cidadania não se constrói, referia Raymundo Faoro, quando a cidade é "[...] dominada por um conselho noturno, como dizia Platão, um conselho que muda à noite tudo o que se decidiu durante o dia" (FAORO, 2008, p. 192).

De toda a forma, para Vittorio Possenti ${ }^{21}$, o bem comum se apresenta como constitutivo de um novo modelo de sociedade é "o" objetivo que cada comunidade deve buscar. $\mathrm{O}$ autor apresenta nove aspectos que compõe a construção de um conceito de bem comum, por isso, passaremos a analisá-lo na seção que segue:

a) O bem comum como meta. Para Possenti, o bem comum é sempre uma meta a ser alcançada (obiettivo da raggiungere). Com efeito, é por esse pressuposto que a conceituação do bem comum afasta peremptoriamente a noção de bem comum como aglutinação de bens individuais: o objetivo da sociedade não é um bem individual, mas um bem que se comunica entre todas as pessoas do grupo indistintamente. Como se percebe, não há eliminação da existência da individualidade, mas, sim, a projeção do coletivo. Nesse sentido, é perceptível que o direito à terra não apenas possui um cariz individual, mas é aquele direito que diz respeito a um quadro social, que importa a coletividade, que assume uma característica transcendente àqueles que pertencem a determinada comunidade.

b) O bem comum como fim. O bem comum é um objetivo e não um meio. É um bem intrínseco da comunidade política o qual pode e deve ser comunicável e exige a participação de todos, não no sentido utilitarista (como meio de felicidade de cada cidadão), mas como princípio de vida. Possenti o define como um communicatio in bene vivendo ${ }^{22}$.

c) O bem comum em três dimensões. O bem comum é composto por elementos materiais, intelectuais e morais. Os componentes do bem comum ultrapassam (mas não prescindem) os níveis morais, éticos e políticos do bem viver. Ora, bem viver em qualquer município significa ter as condições materiais, intelectuais e morais asseguradas pela política pública que, por sua vez, é um bem comum. Desse modo, o bem viver não responsabiliza apenas os governantes.

d) $O$ bem comum como justificativa da autoridade. Trata-se de um elemento conceitual importante na construção do conceito. O bem comum encontra-se fortemente vinculado a justificativa da autoridade, porquanto a legitimidade e a justiça 
da atuação estatal são a razão de ser do próprio poder público ${ }^{23}$. Por isso, além da dimensão local, há a dimensão global, mas sempre reforçando a própria comunidade.

e) $O$ bem comum e o bem público. $\mathrm{O}$ bem comum diz respeito à sociedade política, não somente ao Estado. Não há uma correlação entre o bem público e o bem comum. O bem público é aquele vinculado ao funcionamento da máquina estatal, da ordem pública e do direito. Entretanto, o governo como gestor do Estado também é responsável pela persecução do bem comum.

f) O conteúdo do bem comum. O conteúdo do bem comum não se define somente a priori, mas está vinculado com outros aspectos: debate público, hábitos virtuosos, consenso e evolução social. A conceituação da saúde como bem da comunidade passa (ou passou) por esse filtro. Pela história recente, o direito fundamental à saúde foi amalgamado no texto constitucional e as formas de implementação foram previstas na legislação infrafundamentalis. Embora complexa, a sociedade contemporânea, caracterizada pelo seu caráter pluralista, acabou ampliando sua capacidade institucional de efetivar discursos, dentre os quais a da participação na vida em comunidade.

g) O bem comum e o mérito. Para Possenti, o mérito é a medida de atuação do indivíduo no bem comum. Destaca que o bem comum não pode ser representado por uma teoria simétrica a partir do esquema de que "quem contribui mais recebe mais". Pelo contrário, a distribuição do bem comum se dá conforme as necessidades. Nesse sentido, a autoridade administrativa tem o dever de realocar sua atuação de acordo com a necessidade de distribuição e com as carências de efetividade de direitos. O processo não prestigia as preferências, mas uma noção de finalidade compartilhada por toda a sociedade.

h) O conceito de bem comum é aberto. Para Possenti, "il concetto di bene comune come scopo della società politica è intrinsecamente proporzionale e aperto". Em outras tintas, significa dizer que seu conceito pode ser delimitado/ampliado dentro do grupo social. De modo algum, é um conceito fechado, inalterável. Portanto, o conteúdo do bem comum é preenchível pela própria sociedade.

i) Pressupostos para a realização do bem comum. Para que o bem comum possa ser realizado de modo qualificado é imprescindível (i) instituições comprometidas com o respeito aos direitos fundamentais; (ii) que difunda a ideia de sociedade como associação e do dever de cooperação entre os indivíduos, mantendo a natural diferença R. Fac. Dir. UFG, v. 42, n. 1, p.11-31, jan/abr. 2018 
A terra como bem-comum na memória do direito brasileiro

intelectual e diferenças de escolha valorativas e de propósitos; (iii) a difusão da ideia de codivisão de bens, valores e fins. Esses pressupostos estribam-se no que Possenti defende ao dizer que "bene comune significa che i cittadini condividono almeno alcune verità pratiche, ciò̀ una "fede pratica", alcuni fini sociali o scopi condivisi: il bene comune accomuna.

Diante das conceituações e análises acima descritas, verificamos que estes aspectos implicam o resgate do sentido de comunidade, da terra como bem comum de todos, a qual pode ser identificada com toda sua força e ambivalência em âmbito local, em que pese a importância do global em meio à sociedade cosmopolita. Isso porque, sempre que se busca a efetivação do direito à terra, pensa-se em núcleos menores, como, por exemplo, o município dentro da divisão do território brasileiro. Todavia, paradoxalmente, é este mesmo município que acaba por ser esquecido quando dos investimentos em políticas públicas relacionadas à terra e à propriedade. Por esse esquecimento é que devemos estudar a memória do direito à terra no Brasil, bem como desenvolver estudos visando a sua finalidade de bem comum da humanidade.

\section{CONSIDERAÇÕES FINAIS}

Rememora-se a frase de Cora Coralina em "O Cântico da Terra", utilizada no início deste artigo: A terra é a vida e a vida só é possível através da terra. A vida, como direito humano, deve ser preservada da melhor forma. Da mesma maneira, a terra, como bem comum da humanidade, deve ser preservada e utilizada de forma racional e igualitária entre todos. Nesta pesquisa, objetivamos desvelar alguns paradoxos do direito à terra no Brasil.

Buscamos responder ao seguinte problema de pesquisa: Atualmente, podemos falar na terra como um bem comum da humanidade? Quais são os aspectos históricos relacionados ao acesso à terra no Brasil que contribuem para a dificuldade de se concretizar o objetivo programático de melhorar a distribuição da terra no país até o período pré-Constituição de 1988 ? 
Para isso, utilizou-se da memória como forma de recordar a história do Brasil, em especial, aqueles fatos relacionados ao direito e à terra. Por meio desse norte, apresentamos o decorrer histórico do acesso à terra no Brasil, bem como as suas mais diversas concepções ao longo dos tempos. A construção da ideia de terra como um bem comum da humanidade, passa pela cooperação entre o local e o global. Na relação local/global, o Direito Fraterno aponta para a reflexão de que o local não pode nunca estar só. Esse pressuposto se acentua ainda mais quando se fala dos bens comuns da humanidade, onde os confins são ilimitados.

Observou-se que o acesso normatizado à terra no Brasil por meio da regulamentação das doações no período Imperial e da compra e venda no período Republicano nunca esteve acessível de forma igualitária aos brasileiros. A ocupação informal de terras surgiu como a única forma mediante a qual os estratos menos favorecidos economicamente podiam trabalhar e produzir no campo.

A memória construída historicamente demonstra que o direito, ao estabelecer as diretrizes do que era o acesso lícito e, consequentemente, do ilícito, contribuiu para reforçar as desigualdades no âmbito rural e a estigmatização das formas populares de acesso à terra. Isso tudo ao menos até a Constituição da República de 1988 que, ao lado do direito fundamental à propriedade, estabeleceu como condição que ela seja capaz de cumprir a sua função social.

Esse resgate da memória histórica brasileira é fundamental para a compreensão da importância da divisão de terras, da prometida reforma agrária e da legitimidade dos movimentos sociais que protestam pela concretização desses objetivos constitucionais. Explica, também, a resistência dos grupos de poder econômico e dos grandes proprietários de terras no Brasil em contribuir para uma reforma agrária mais ampla, que realmente efetive a terra como bem comum de todos. Construir memórias não deixa de ser uma forma de luta por direitos e por justiça social.

\section{REFERÊNCIAS BIBLIOGRÁFICAS}

CASTRO, Flávia Lages de. História do Direito: geral e Brasil. Rio de Janeiro: Lumen Juris, 2003.

CERQUEIRA, Laurez. Florestan Fernandes: vida e obra. São Paulo: Expressão Popular, 2004. 
FAORO, Raymundo. A Democracia Traída. São Paulo: Globo, 2008.

GONÇALVES, Vanessa Chiari. A criminalização das ações dos movimentos campesinos no Brasil: uma reflexão a partir da criminologia crítica. In: Anais do XVIII Congresso Nacional do CONPEDI, realizado em São Paulo - SP nos dias 04, 05, 06 e 07 de novembro de 2009, p. 1906. Disponível em: <http://www.publicadireito.com.br/conpedi/manaus/arquivos/anais/saopaulo/2907.pdf $>$. Acesso em 12 out. 2017.

LOPES, José Reinaldo de Lima. O direito na história: lições introdutórias. 2. ed. São Paulo: Max Limonad, 2002.

PAZ, Octavio. El labirinto de la soledad. México. Fondo de Cultura Económica, 2004, p. 79

POSSENTI, Vittorio. La società liberali al bivio. Turim: Marietti, 1991.

RAMPINELLI, Waldir José e OURIQUES, Nildo Domingos (orgs). Os 500 Anos: a conquista interminável. Petrópolis: Vozes, 1999.

RESTA, Eligio. O direito fraterno. Tradução de Sandra Regina Martini. Santa Cruz do Sul: Editora EDUNISC, 2004.

Il diritto fraterno. Roma: Laterza, 2005.

RICOVERI, Giovanna. Beni comuni: fra tradizione e futuro. Bologna: Editrice Missionaria Italiana, 2005.

VIAL, Sandra Regina Martini. Propriedade da Terra: análise sociojurídica. Porto Alegre: Livraria do Advogado, 2003.

ZAMBRANO, Viriginia; VIAL, Sandra. Stato e Diritti nella'età della Globalizzazione. Salerno: Brunolibri, 2010.

Artigo recebido em 25 de fevereiro de 2018 e aceito em 14 de maio de 2018

\footnotetext{
${ }^{1}$ Interessante a observação de Octávio Paz (2004, p.12): "Despertar a la historia significa adquirir conciencia de nuestra singuralidad, momento de reposo reflexivo antes de entregarmos al hacer.".

2 "Va precisato che per beni comuni non si intendono solo le risorse naturali in quanto tali, ma anche gli usi civici o diritti collettivi d'uso da parte di una data comunita a godere dei frut ti di
} 
quella data risorsa, sia essa terra, pascolo o area forestale. Quel che contraddistingue i beni comuni o usi civici la forma partecipata o comunitaria della proprieta o dell'uso delle risorse naturali, che non sono pertanto né pubbliche né private; forma partecipata di proprieta o gestione che persiste nonostante la modernita e i cambiamenti da essa indotti." (RICOVERI, 2005, p.11).

${ }^{3}$ Para mais informações sobre movimentos sociais, em especial a Jornada de Junho que ocorreu em 2013 em Porto Alegre, ver Bonfigli e Schwartz (2017).

4 Conforme Dicionário Aurélio, movimento significa: "ato ou processo de mover-se; deslocamento". (p.1165).

${ }^{5}$ Neste sentido consultar Carl Schmitt, Capítulo 2, Il Diritto Internazionale preglobale”, in Il Nomos della Terra, o qual trata da dificuldade de entender a terra em um sentido global e, por isso, os homens levaram muitos milênios para ter uma experiência científica da terra. Este tema é abordado, também, em outros capítulos do mesmo livro.

${ }^{6}$ Sobre a ideia de futuro da propriedade, Proudhon observa: Mesmo que a nação fosse proprietária, pode a geração de hoje destruir a de amanhã? As pessoas são possuidoras a título de usufruto; o governo governa, superintende, protege as pessoas e aprova decretos de justiça distributiva. Se a nação também faz concessões da terra, ela se limita a conceder o seu uso; de modo nenhum tem o direito de vendê-la ou aliená-la. Não sendo proprietária, como pode alienar a propriedade? Destrua a terra ou (o que dá no mesmo) venda a terra e você não só aliena uma, duas ou mais colheitas, como aniquila todos os produtos que você pode extrair dela - você e os seus filhos e os filhos dos seus filhos.

${ }^{7}$ Para mais informações sobre a criminalização das ações dos movimentos campesinos no Brasil (GONÇALVES, 2009, p. 1906).

${ }^{8}$ In altre parole, per capire il contesto e il contenuto delle lotte per i beni comuni serve un'analisi critica e autoriflessiva delle pratiche istituzionali dello sviluppo, della modernità e dell'imperialismo, e del modo in cui i soggetti dotati di potere (organizzazioni finanziarie internazionali, esperti dello sviluppo, organizzazioni non governative e studiosi) razionalizzano discorsivamente il comporta- mento umano e lo riducono alla metafora dei beni comuni (RICOVERI, 2005, p.29).

9 “Assim a terra resulta ligada ao direito em um tríplice modo: ela o conserva dentro de si, como recompensa pelo trabalho; mostra-o em si, como confim fiel; enfim, o leva sobre si, pelo caráter público do ordenamento. $\mathrm{O}$ direito é terrâneo e referido à terra. È o que intenciona o poeta quando, falando da terra universalmente justa, a define justíssima tellus. Tradução Livre.

${ }^{10}$ A terra não adquire, originariamente, um significado jurídico, porque, na sociedade arcaica, quando podemos mais apropriadamente chamar de comunidade da terra, ainda não se conheciam qualificações dos comportamentos do tipo jurídico. A terra era terra da comunidade. A comunidade era originariamente nômade e identificava-se com a terra a cada nova ocupação. Só com o aproveitamento agrário da terra as comunidades fixaram-se em determinados locais e/ou territórios, mas ainda não era necessário delimitar a terra em modo diferente da delimitação implícita na ocupação. (VIAL, 2003, p.46).

11 "Dom Fernando e d. Isabel, por graça de Deus rei e rainha de Castela, de Leão, de Aragão, da Sicília, de Granada, de Toledo, de Valência, de Galiza, de Maiorca, de Sevilha, da Sardenha, de Córdova, da Córsega, de Múrcia, de Jaém, do Algarve, de Algeciras, de Gibraltar, das ilhas de 
Canária, conde e condessa de Barcelona, senhores de Biscaia e de Molina, duques de Atenas e de Neopatria, condes de Roussilhão e da Sardenha, marqueses de Oristán e de Gociano, juntamente com o príncipe d. João, nosso mui caro e mui amado filho primogênito, herdeiro dos nossos ditos reinos e senhorios"(...). (...) "Dada na vila de Arévalo, aos dois dias do mês de julho, ano do nascimento de nosso senhor Jesus Cristo de mil quatrocentos e noventa e quatro. Eu, el-rei.Eu, a rainha. Eu, o príncipe. E eu, Fernão Dalvares de Toledo, secretário d'el-rei e da rainha, nossos senhores, a fiz escrever por sua ordem." (Disponível em: http://www.colegiomaededeus.com.br/professores/lucila/estudo_b9.htm. Acesso em 19 fev. 2018).

12 “(...) por esta presente carta vos damos todos nossos poderes completos naquela maneira e forma que podemos e em tal caso se requer, especialmente para que por nós e em nosso nome e de nossos herdeiros e sucessores, e de todos nossos reinos e senhorios, súditos e naturais deles, possais tratar, ajustar e assentar e fazer contrato e concórdia com os ditos embaixadores do sereníssimo rei de Portugal, nosso irmão, em seu nome, qualquer concerto, assento, limitação, demarcação e concórdia sobre o que dito é, pelos ventos em graus de Norte e de Sul e por aquelas partes, divisões e lugares do céu, do mar e da terra, que a vós bem visto forem e assim vos damos o dito poder para que possais deixar ao dito rei de Portugal e a seus reinos e sucessores todos os mares, e ilhas, e terras que forem e estiverem dentro de qualquer limitação e demarcação que com ele assentarem e deixarem."

${ }^{13}$ Conceito luhmanniano, que segundo o próprio autor passa a ser identificado somente a partir do séc. XVIII: "In questa società differenziata per funzioni (o a differenziazione funzionale), i sistemi parziali sono diseguali per la funcione Che ciascuno di essi svolge. Ogni sistema parziale si differenzia ed è definito in base alla funzione specifica che svolge nella società: i principali sono il sistema politico, il sistema economico, il sistema della scienza, il sistema dell'educazione, il sistema giuridico, le famiglie, la religione, il sistema della medicina, il sistema dell'arte. La comunicazione fondamentale nella società è quindi strutturata intorno a queste funzioni." Claudio Baraldi e outros. Luhmann in Glossario. Milão: Franco Angeli, 1996, p.89. Tradução: Nesta sociedade diferenciada por funções (ou por diferenciações funcionais), os sistemas parciais são desiguais por sua função que cada um desenvolve. Cada sistema parcial se diferencia e é definido com base na função específica que desenvolve na sociedade: os principais são o sistema político, o sistema econômico, o sistema da ciência, o sistema da educação, o sistema jurídico, as famílias, a religião, o sistema da medicina, o sistema da arte. A comunicação fundamental na sociedade é portanto estruturada em torno destas funções. Tradução livre.

${ }^{14}$ Como foi referido, no período Imperial as terras eram doadas em usufruto hereditário para os cristãos que quisessem trabalhar na terra. Evidentemente que os fidalgos (nobres) tinham a preferência em detrimento da plebe a quem restava acessar a terra por meio da ocupação informal. É importante lembrar que os não cristãos (descendentes de africanos e de indígenas) estavam normativamente excluídos da possibilidade de acesso à terra, sendo-lhes negada, inclusive, a própria condição de humanidade.

15 “Art. 113, 17. É garantido o direito de propriedade, que não poderá ser exercido contra o interesse social ou coletivo, e na forma que a Lei determinar. A desapropriação por necessidade ou utilidade pública far-se-á nos termos da lei, mediante prévia e justa indenização. Em caso de perigo iminente, como a guerra ou comoção intestina, poderão as autoridades competentes usar da propriedade particular até onde o bem público o exija, ressalvado o direito de indenização ulterior".

${ }^{16}$ Para este estudo, importante observar as recentes decisões judiciais acerca do direito à terra e à propriedade. Alguns casos: Apelação Cível N $\mathrm{N}^{\circ} 70075451740$, Vigésima Câmara Cível, Tribunal de Justiça do RS, Relator: Carlos Cini Marchionatti, Julgado em 13/12/2017. Agravo 
de Instrumento $N^{\circ}$ 70074133331, Décima Oitava Câmara Cível, Tribunal de Justiça do RS, Relator: Pedro Celso Dal Pra, Julgado em 14/09/2017. Apelação Cível No 70068019579, Décima Oitava Câmara Cível, Tribunal de Justiça do RS, Relator: Marlene Marlei de Souza, Julgado em 29/08/2017.

${ }^{17}$ Sobre isso ver: "Stato e Diritti nella' età della Globalizzazione", as reflexões sobre o tema em especial: "Sì che l'interrogativo da cui abbiamo preso le mosse ritorna con puntuale regolarità: a chi appartengono i beni comuni della umanità? Chi li deve proteggere e da chi? Il diritto qui mostra i suoi limiti. Le relazioni di proprietà si modificano nel corso del tempo e il diritto non riesce a seguire tali evoluzioni. Queste sono alcune delle domande cui il diritto deve dare una risposta. Non si tratta di questioni squisitamente giuridiche ma, piuttosto, di natura politicogiuridica (e che forse investe anche altre aree del sapere, come la poesia). In tali situazioni lo stato è chiamato a delimitare le sue stesse competenze."(ZAMBRANO; VIAL, 2010, p.84).

${ }^{18} \mathrm{O}$ catálogo de teses e dissertações da Capes (http://catalogodeteses.capes.gov.br/catalogoteses/\#!/) é uma ferramenta de pesquisa para analisar os trabalhos sobre terra que foram desenvolvidos. Realizando a pesquisa com a palavra "terra", apareceram 114.581 trabalhos, das mais diversas áreas do conhecimento. Redefinindo a área de conhecimento para "Direito" somente, apareceram 526 trabalhos.

19 Tutte le cose utili alla vita dell'uomo nascono dalla terra; ma poche cose nascono nella condizione richiesta per utilizzarle. Quindi occorre che vi sia, oltre al contadino e al proprietario terriero, un'altra classe di uomini che, ricevendo da essi le materie prime, le lavorino nella forma adatta e ne trattengano una parte per il proprio uso e mantenimento. (HUME, 1974, p.492). "Todas as coisas úteis à vida do homem nascem da terra; mas poucas coisas nascem na condição exigida para utilizá-las. Por isso, ocorre que exista além do camponês e do proprietário de terra, uma outra classe de homens que, recebendo destes as matérias-primas, trabalhe-as na forma adaptada e retenham uma parte para seu próprio uso e manutenção". Tradução livre.

20 'L'erosione degli spazi pubblici dell'amicizia e il suo rintanarsi nei retrobottega della vita privata è ovviamente effetto e non causa di profondi processi di mutamento. Sarebbe interessante ripercorrere i tragitti dell'amicizia accanto a quelli del dono, come a fatto Derrida, e della solidarietà per capire quanto della semantica prodotta dai sistemi sociali sia stata depositaria di tracce che mostrano la progressiva riduzione di una dimensione comunitaria." (RESTA, 2005, p.13).

${ }^{21}$ Para mais informações sobre bem-comum no estudo de Vittorio Possenti, ver o Capítulo III de sua obra (POSSENTI, 1991, capítulo III).

${ }^{22}$ Importante observar as disposições da Agenda 2030 sobre a terra e a propriedade. No objetivo $\mathrm{n}^{\mathrm{o}}$ 1: "Acabar com a pobreza em todas as suas formas, em todos os lugares", a meta $\mathrm{n}^{\mathbf{0}} 1.4$ dispõe que "Até 2030, garantir que todos os homens e mulheres, particularmente os pobres e vulneráveis, tenham direitos iguais aos recursos econômicos, bem como o acesso a serviços básicos, propriedade e controle sobre a terra e outras formas de propriedade, herança, recursos naturais, novas tecnologias apropriadas e serviços financeiros, incluindo microfinanças" (Disponível em: https://nacoesunidas.org/pos2015/agenda2030/. Acesso em 19 fev. 2018).

23 "La non-evidenza del bene comune, il fatto che esso sia sempre soggetto ad un velo di ignoranza sono i motivi che postulano la necessità dell'autorità politica; il suo compito consiste nell'assicurare l'unità di azione del corpo politico, al cui interno generalmente esistono molteplici opinioni sugli scopi e le azioni da intraprendere ... Funzione dell'autorità è garantire l'intenzione materiale, e non solo formale, del bene comune: questo non implica che il compito 
A terra como bem-comum na memória do direito brasileiro

delle singole persone sia sottovalutato, perché il bene comune è prodotto in tanta parte dagli sforzi cooperativi dei singoli, dal retto uso delle loro ragion pratiche, dalle infinite scelte compiute a tutti i livelli della vita sociale." 